\title{
Expression and effect of CXCL14 in colorectal carcinoma
}

\author{
KEZHI LIN ${ }^{1 *}$, RUANMIN ZOU ${ }^{2 *}$, FENG LIN $^{3}$, SHUANG ZHENG $^{3}$, XIAN SHEN $^{4}$ and XIANGYANG XUE ${ }^{5}$ \\ ${ }^{1}$ Experimental Teaching Center, Wenzhou Medical University; ${ }^{2}$ Department of Obstetrics and Gynecology, The First Affiliated \\ Hospital, Wenzhou Medical University, Wenzhou, Zhejiang 325035; ${ }^{3}$ Department of General Surgery, Taizhou First People's \\ Hospital, Taizhou, Zhejiang 318020; ${ }^{4}$ Department of Gastrointestinal Surgery, The First Affiliated Hospital, \\ Wenzhou Medical University; ${ }^{5}$ Department of Microbiology and Immunology, Institute of Molecular \\ Virology and Immunology, Wenzhou Medical University, Wenzhou, Zhejiang 325035, P.R. China
}

Received February 9, 2014; Accepted May 30, 2014

DOI: $10.3892 / \mathrm{mmr} .2014 .2343$

\begin{abstract}
Chemokines are important in the proliferation and metastasis of tumors. CXCL14 is a member of the CXCL chemokine family and exhibits various expression patterns in different types of tumor, even those tumors that occur in the same type of tissue. The expression of CXCL14 and its clinical significance in colorectal carcinoma are unclear. In the present study, the expression levels of CXCL14 in colorectal carcinoma and adjacent normal tissues were detected using reverse transcription-quantitative polymerase chain reaction and immunohistochemistry. Kaplan-Meier survival curves and the Cox regression model were applied to evaluate the clinical significance of the expression levels of CXCL14 in colorectal carcinoma compared with those in normal tissues. To investigate the effects at a cellular level, a replication-defective lentivirus overexpressing CXCL14 was constructed and transfected into HT29 colorectal carcinoma cells. The effect of CXCL14 on the proliferation of colorectal carcinoma cells and the change in cell cycle distributions were investigated using a cell counting kit- 8 assay and flow cytometry, respectively. Results of the current study indicated that the expression levels of CXCL14 mRNA and protein in colorectal carcinoma were markedly reduced compared with levels in normal tissues $(\mathrm{P}<0.05)$. The clinical correlation analysis suggested that downregulation of CXCL14 expression
\end{abstract}

Correspondence to: Dr Feng Lin, Department of General Surgery, Taizhou First People's Hospital, No. 218 Hengjie Street, Huang Yan District, Taizhou, Zhejiang 318020, P.R. China

E-mail: linfeng0316@aliyun.com

Dr Xiangyang Xue, Department of Microbiology and Immunology, Institute of Molecular Virology and Immunology, Building No. 7, Wenzhou Medical University, Chashan University Town, Wenzhou, Zhejiang 325035, P.R.China

E-mail:wzxxy001@163.com

${ }^{*}$ Contributed equally

Key words: colorectal carcinoma, chemokine, CXCL14, lentivirus, survival analysis in tumors was associated with lymph metastasis, tumor location, and clinicopathological stage $(\mathrm{P}<0.05)$. Kaplan-Meier survival analysis revealed that downregulation of CXCL14 expression was correlated with a poor prognosis $(\mathrm{P}<0.01)$. Overexpression of CXCL14 by lentiviral transfection produced an inhibitory effect on cell proliferation by arresting the cell cycle in the $\mathrm{G}_{1}$ stage. The data of the current study suggest that CXCL14 may be involved in the development and progression of colorectal carcinoma, and may act directly as a potential cancer suppressor gene. The level of CXCL14 expression may be a valuable adjuvant parameter in predicting the prognosis of colorectal carcinoma and may be a potential therapeutic target.

\section{Introduction}

Colorectal carcinoma is the third most common type of malignant tumor worldwide, and resulted in $\sim 400,000$ deaths in 2010 (1). Although treatments have greatly improved in recent years, the five-year survival rate of advanced colorectal carcinoma has not significantly improved. Thus far, the pathogenesis of colorectal carcinoma has not been clearly characterized.

The microenvironment of tumors has increasingly been recognized as having an important role in the occurrence and development of cancer (2). Chemokines and their receptors can induce migration, chemotaxis and rearrangement of the cytoskeleton in the target cell, and therefore promote multiple physiological functions of cells, including cell growth, development, differentiation and apoptosis (3-5). It has been reported that chemokine receptors and their functions differ between tumor cells and normal cells, suggesting that dysregulation of chemokines may be involved in the development of malignancy $(6,7)$. It has been demonstrated that the expression levels of the receptor CCR6 are associated with the metastasis of hepatocellular carcinoma (8) and lymphatic metastasis in colorectal carcinoma (9). In addition, studies conducted by Hojo et al (10) indicated that high CXCL16 expression levels are associated with good prognosis in colorectal carcinoma (10).

Using the Expressed Sequence Tags database, Hromas et al (11) described a novel CXC chemokine located in human kidney and breast tissue, termed BRAK, which is now termed CXCL14 (11). CXCL14 is highly concentrated in 
normal cells, but is mostly absent from cancer cells $(12,13)$. Due to its ELR-motif, CXCL14 exhibits multiple functions, including an inhibitory effect on angiogenesis and chemotactic effect on natural killer cells, B-cells, macrophages, monocytes and immature dendritic cells (14-18). The identification of CXCL14 led to clinical research into other diseases, including obesity $(19,20)$, bacterial infections $(21)$ and immune system disorders $(22,23)$. In addition to breast cancer tissues, studies have demonstrated low or absent CXCL14 expression in other tissues, including lung cancer, head and neck squamous cell carcinoma, hepatocellular carcinoma and gastric cancer (23-28). However, in prostate and pancreatic cancer, CXCL14 is generally expressed at a high level (29-31). Different studies have reported varied expression levels within one tissue type; Zeng et al (32) observed that CXCL14 expression levels were higher in colorectal carcinoma tissue than in normal tissues, while Cao et al (33) produced an opposite result. As a homeostasis-associated chemokine, CXCL14 may function in the development of colorectal carcinoma by blocking the chemotaxis of immune cells. However, its role in the genesis and development of colorectal carcinoma as either an anti-oncogene or an oncogene is not entirely clear. In the present study, the expression of CXCL14 and its clinical significance in colorectal carcinoma tissues were investigated, and the direct effect of CXCL14 on colorectal carcinoma cells was evaluated by upregulating CXCL14 expression.

\section{Materials and methods}

Collection and processing of tissue specimens. Tumor samples were collected from 40 patients with colorectal carcinoma that were diagnosed by endoscopic biopsy and surgically treated in Taizhou First People's Hospital (Taizhou, China) between December 2008 and April 2009. The diagnoses of colorectal cancer in all patients were confirmed after surgery by histopathological examination according to World Health Organization standards (34). The clinicopathological features of the patients are listed in Table I. None of the patients had received preoperative radiotherapy or chemotherapy and all patients received strict chemotherapy following surgery according to the colorectal carcinoma treatment guidelines stipulated by National Comprehensive Cancer Network (35). Tumor samples were paired with normal tissues that had been resected from a location $2 \mathrm{~cm}$ away from the edge of the tumor. Each sample was divided into two further samples. One was cryopreserved in liquid nitrogen within $30 \mathrm{~min}$ of removal for RNA extraction, and the other was formalin-fixed and embedded in paraffin for sectioning and immunohistochemical analysis. Informed written consent was obtained from each patient and the study was approved by the Human Research Ethics Committee of Taizhou First People's Hospital.

Reverse transcription-quantitative polymerase chain reaction $(R T-q P C R)$. Total RNA extraction was conducted using TRIzol reagent (Invitrogen Life Technologies, Carlsbad, CA, USA) according to the manufacturer's instructions. In order to remove any DNA, the extracted RNA was processed using DNase I (Takara Bio, Inc., Shiga, Japan) with phenol-chloroform extraction (Kangwei Biological Company, Beijing, China). The purified RNA was dissolved in diethylpyrocarbonate water
Table I. Clinicopathological features and CXCL14 protein expression of 40 specimens.

\begin{tabular}{|c|c|c|c|}
\hline Clinical feature & $\mathrm{n}$ & $\begin{array}{l}\text { Relative protein } \\
\text { expression }\end{array}$ & P-value \\
\hline Gender & & & $>0.05$ \\
\hline Male & 30 & $0.183(0.007-1.151)$ & \\
\hline Female & 10 & $0.157(0.005-0.035)$ & \\
\hline Age (years) & & & $>0.05$ \\
\hline$<60$ & 6 & $0.217(0.028-0.096)$ & \\
\hline$\geq 60$ & 34 & $0.170(0.006-1.164)$ & \\
\hline Tumor size $(\mathrm{cm})$ & & & $>0.05$ \\
\hline$<5$ & 20 & $0.178(0.002-1.56)$ & \\
\hline$\geq 5$ & 20 & $0.176(0.001-0.107)$ & \\
\hline $\begin{array}{l}\text { Lymph node } \\
\text { metastasis }\end{array}$ & & & $<0.05$ \\
\hline Present & 22 & $0.146(0.006-0.061)$ & \\
\hline Absent & 18 & $0.215(0.004-0.120)$ & \\
\hline Tumor infiltration & & & $>0.05$ \\
\hline Serosal layer & 16 & $0.176(0.001-0.106)$ & \\
\hline Serous outer & 20 & $0.173(0.003-0.161)$ & \\
\hline Subserosa & 2 & 0.243 & \\
\hline Muscular layer & 2 & 0.152 & \\
\hline Tumor location & & & $<0.05$ \\
\hline Rectum & 20 & $0.146(0.006-1.283)$ & \\
\hline Colon & 20 & $0.206(0.009-0.047)$ & \\
\hline Anatomical stage ${ }^{a}$ & & & $<0.05$ \\
\hline I, II & 18 & $0.215(0.004-1.200)$ & \\
\hline III, IV & 22 & $0.146(0.005-0.061)$ & \\
\hline CEA $(\mu \mathrm{g} / 1)$ & & & $>0.05$ \\
\hline$\leq 5$ & 18 & $0.200(0.001-1.351)$ & \\
\hline$>5$ & 22 & $0.158(0.004-0.124)$ & \\
\hline
\end{tabular}

Relative protein expression is presented as medain (25th-75th percentile). ${ }^{a} \mathrm{NCCN}$ Guideline 2013 Colorectal Cancer Staging; CEA, carcinoembryonic antigen.

(Takara Bio, Inc.) and its concentration was measured with an ultraviolet spectrophotometer (DU640; Beckman Coulter, Miami, FL, USA), prior to storage at $-80^{\circ} \mathrm{C}$. Extracted RNA $(1 \mu \mathrm{g})$ was taken from each sample for reverse transcription using Oligo dT primers (ReverTra Ace qPCR RT kit, Toyobo, Osaka, Japan). The reaction conditions were as follows: $42^{\circ} \mathrm{C}$ for $60 \mathrm{~min}, 75^{\circ} \mathrm{C}$ for $15 \mathrm{~min}$, followed by $-20^{\circ} \mathrm{C}$ at the end of the reaction. qPCR was conducted based on a $15 \mu \mathrm{l}$ reaction system. Table II lists the primer sequences used in the analysis. The quantitative fluorescent PCR reaction system consisted of the following: $1 \mu \mathrm{l}$ reverse transcription product, 1X SYBR-Green I Mastermix (Toyobo), and $0.5 \mu \mathrm{mol} / 1$ each of the specific forward and reverse primers. The reaction conditions were as follows: 40 cycles of $95^{\circ} \mathrm{C}$ for $2 \mathrm{~min}, 95^{\circ} \mathrm{C}$ for $15 \mathrm{sec}$ and $60^{\circ} \mathrm{C}$ for $1 \mathrm{~min}$. qPCR was conducted using the CFX96 Real-Time PCR Detection system (Bio-Rad, Hercules, CA, USA). All samples were run in triplicate to increase 
Table II. Primer sequences.

Product

Gene

Direction

Primer sequence

length (bp)

$\begin{array}{lll}\text { CXCL14 } & \text { F } & \text { 5'-AGCCAAAGTACCCGCACTG-3' } \\ & \mathrm{R} & \text { 5'-AGACCCTGCGCTTCTCGTTC-3' } \\ \text { GAPDH } & \mathrm{F} & \text { 5'-CAGGGCTGCTTTTAACTCTGGTAA-3' } \\ & \mathrm{R} & \text { 5'-GGGTGGAATCATATTGGAACATGT-3' }\end{array}$

bp, base pair; F, forward; R, reverse.

reliability of results. Based on the $\mathrm{Ct}$ values of the specimens using GAPDH as the normalizer gene, the relative quantitative method of qPCR was adopted. $\mathrm{N}=2^{-\Delta \Delta \mathrm{Ct}}$ was considered to represent the CXCL14 relative expression level in specimens, where, $\Delta \Delta \mathrm{Ct}=\left(\mathrm{Ct}_{\mathrm{CXCL} 14}-\mathrm{Ct}_{\mathrm{GAPDH}}\right)$ tumor - $\left(\mathrm{Ct}_{\mathrm{CXCL} 14}-\mathrm{Ct}_{\mathrm{GAPDH}}\right)$ normal.

Immunohistochemical detection. Formalin-fixed specimens embedded in paraffin were sectioned into $4-\mu \mathrm{m}$ samples. The slides were processed with $0.1 \%$ poly-L-lysine and tissues were dewaxed using dimethyl benzene followed by immersion in distilled water. Endogenous peroxidase activity was inhibited by incubation in a $0.3 \%$ hydrogen peroxide bath for $10 \mathrm{~min}$ followed by three washes with $0.01 \mathrm{~mol} / 1$ phosphate-buffered saline (PBS; pH 7.4). Slides were then immersed in citrate antigen retrieval buffer (Zhongshan Golden Bridge Biotechnology, Beijing, China) for $1.5 \mathrm{~min}$. Once the slides were cooled to room temperature, they were washed with PBS three additional times, followed by blocking in sheep serum for $2 \mathrm{~h}$. The sections were incubated in primary anti-CXCL14 antibody (Abcam, Cambridge, MA, USA) diluted to 1:500 in $\mathrm{PBS}$, in a humidified chamber at $4^{\circ} \mathrm{C}$ overnight. Sections were then incubated in horseradish peroxidase (HRP)-conjugated secondary goat anti-mouse antibodies (MaiXin Bio, Fuzhou, China) at $37^{\circ} \mathrm{C}$ for $30 \mathrm{~min}$. The color reaction was developed using a 3,3'-diaminobenzidine kit (Zhongshan Golden Bridge Biotechnology) according to the manufacturer's instructions. Slides were then counterstained using hematoxylin, dehydrated and sealed with neutral gum. In the negative control group, PBS was used in place of the primary antibody. As CXCL14 is located in the plasma, cells stained with brown cytoplasm were considered as positive for CXCL14. Image-Pro Plus, version 6.0 image processing software (Media Cybernetics, Rockville, MD, USA) was used to calculate the mean optical density for further statistical analyses.

Construction of overexpressed CXCL14 lentivirus. In order to facilitate the CXCL14 expression analysis, the study adopted the pLenti6.3_MCS_IRES-EGFP lentivirus expression vector (Invitrogen Life Technologies) with an internal ribosome entry site (IRES). The full-length sequence of CXCL14 (accession no. BC003513.1) was synthesized by Invitrogen and cloned into the plasmid of pLenti6.3_MCS_IRES-EGFP using Nhel and Ascl (Toyobo) double enzyme digestion. The pLenti6.3_CXCL14_IRES-EGFP recombinant plasmid was then identified by CXCL14 gene-specific PCR and sequencing analysis. The plasmid was extracted using a PureLink HiPure Plasmid Maxiprep kit (Invitrogen Life Technologies) in preparation for the lentivirus package. To obtain the lentivirus, 293T cells (ATCC, Manassas, VA, USA) at logarithmic phases were transformed with the packaged plasmids of pLP1, pLP2, pLP/VSVG and pLenti6.3_CXCL14_IRES-EGFP lentivirus expression plasmid at a ratio of $3: 1$ according to manufacturer's instructions of Lipofectamine 2000 (Invitrogen Life Technologies). After $48 \mathrm{~h}$, the cell culture supernatant was collected and centrifuged at 3,000 x g for $10 \mathrm{~min}$ to remove the residual cells and fragments. The virus supernatant was then ultracentrifugated at 50,000 x g for $2 \mathrm{~h}$, and the concentration was resuspended in Opti-MEM solution (Invitrogen, Life Technologies). Following titer determination, the virus solution was stored at $-80^{\circ} \mathrm{C}$.

Western blot analysis. HT29 colorectal carcinoma cells (ATCC) were transfected by CXCL14 lentivirus with a multiplicity of infection (MOI) of 20, and total protein was extracted with a protein extraction kit (Shanghai Biyuntian Biological Co., Ltd, Shanghai, China) following $48 \mathrm{~h}$ of infection. Extracted protein $(20 \mu \mathrm{g})$ was then separated by $10 \%$ SDS-PAGE gel electrophoresis and transferred onto polyvinylidene fluoride membranes (Millipore, Billerica, MA, USA). After blocking with 5\% non-fat milk for $2 \mathrm{~h}$, the membranes were then incubated with the CXCL14 monoclonal antibody $(1: 100,000)$ at $4^{\circ} \mathrm{C}$ overnight. Following three cycles of washing with Tris-buffered saline and Tween-20, HRP-conjugated goat anti-mouse antibodies (Beyotime Biotech, Shanghai, China) were incubated for $2 \mathrm{~h}$ at room temperature. A BeyoECL Plus (Beyotime Biotech) detection system was used for analysis of the final chemiluminescence reaction. The samples of HT29 colorectal carcinoma cell lines transfected with the control lentivirus were regarded as negative controls and $\beta$-actin served as an internal reference gene.

Cell proliferation and activity detection. HT29 colorectal carcinoma cell lines were cultured in a 96-well plate and were transfected with CXCL14 lentivirus at an MOI of 20. Following 48-h culture, the activity of the cells was detected with a cell counting kit- 8 assay kit (Beyotime Biotech). The absorbency was measured with a spectrophotometer (BioTek, Winooski, VT, USA) at a wavelength of at $450 \mathrm{~nm}$ according to the manufacturer's instructions, and cell viability was calculated.

Cell cycle detection by flow cytometry (FCM). The transfected HT29 cells were digested with $0.25 \%$ pancreatic enzymes, 
A

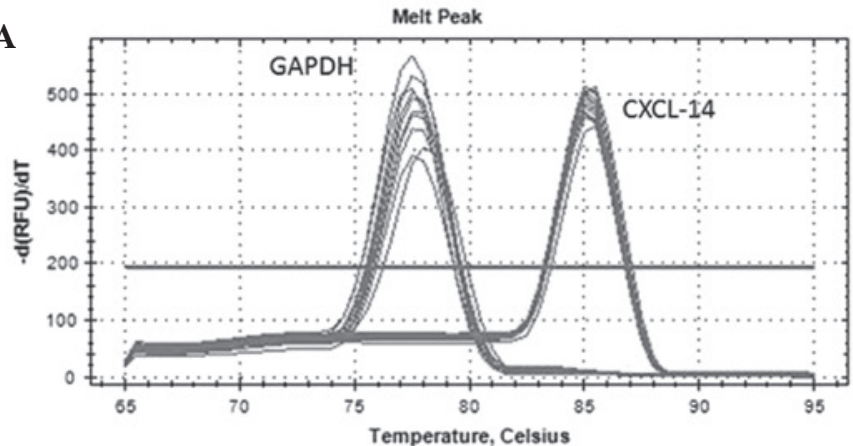

C

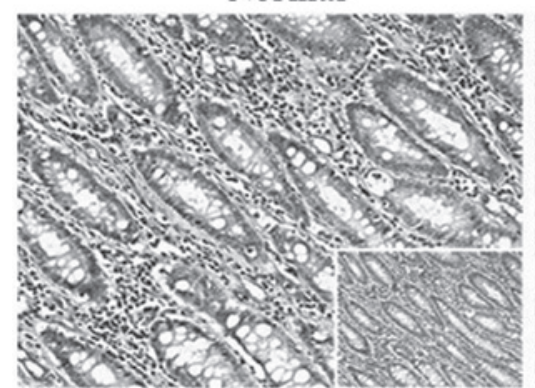

Tumor

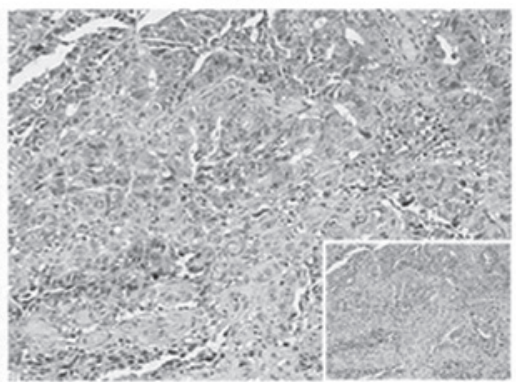

B

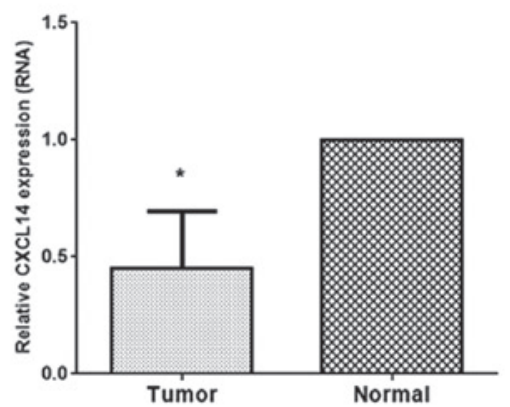

D

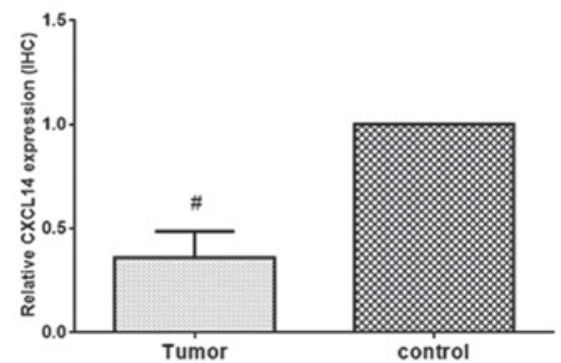

Figure 1. Expression of CXCL14 and survival analysis. (A) Melt curve presenting expression of CXCL14 mRNA. (B) Relative RNA expression of CXCL14. * $<0.01$ vs. normal, $\mathrm{n}=20$. (C) CXCL14 was detected with immunohistochemical staining (magnification, $\mathrm{x} 200$ ). (D) Relative protein expression of CXCL14. ${ }^{\text {P }}<0.01$ vs. normal, $\mathrm{n}=20$.

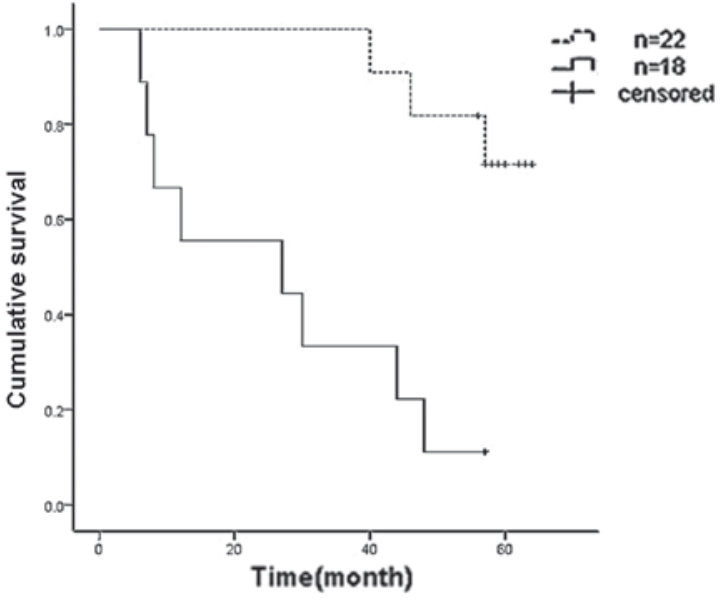

Figure 2. Survival curves for patients with high and low expression of CXCL14 as determined by immunohistochemistry. Dotted curve, high expression group. Average optical density $>1 / 3$ (tumor vs. normal); Solid line, low expression group. Average optical density $\leq 1 / 3$ (tumor vs. normal). Censored indicates patients who failed to respond.

then centrifuged at $800 \mathrm{x} \mathrm{g}$ for $10 \mathrm{~min}$. Following washing, the cells were infiltrated and fixed with $70 \%$ precooled ethyl alcohol at $4^{\circ} \mathrm{C}$ overnight. After washing twice with PBS, the cells were digested by RNase-A (Toyobo) at $37^{\circ} \mathrm{C}$ for $30 \mathrm{~min}$. The cells were stained with propidium iodide in an ice bath in the dark for $30 \mathrm{~min}$, then filtered. Flow cytometry (BD Biosciences, San Jose, CA, USA) was utilized for analytic detection (Beckman Coulter, Brea, CA, USA).

Statistical analysis. The Wilcoxon signed-rank test was adopted for the comparison of paired samples; the
Mann-Whitney U test was applied for the comparison of two groups of independent samples; the Kruskal-Wallis H test was applied for the comparison of three or more groups of independent samples; the $\chi^{2}$ test was adopted for the comparison of inter-group rates; and the association between CXCL14 protein expression and prognosis was analyzed with a Kaplan-Meier survival curve. $\mathrm{P}<0.05$ was considered to represent a statistically significant difference. All the analyses were conducted using SPSS, version 19.0 (IBM SPSS, Armonk, NY, USA).

\section{Results}

Expression of CXCL14 in colorectal carcinoma tissues. The expression levels of CXCL14 mRNA in colorectal carcinoma were analyzed using RT-qPCR, with GAPDH as an internal reference. The melting curves of CXCL14 and GAPDH were sharply defined curves with a narrow peak, indicating that the established PCR method effectively amplified the target genes (Fig. 1A). As seen in Fig. 1B, the relative level of CXCL14 expression in tumor specimens was 0.502, which was significantly lower than the level in paired normal tissues $(\mathrm{P}<0.01)$. The CXCL14 protein expression level was further analyzed by immunohistochemical analysis. The expression of CXCL14 protein was observed in the cytoplasm (Fig. 1C). In normal tissues, there was strong positive staining, while the tumor tissues expressed CXCL14 at a low level, if at all. Semi-quantitative analyses of immunohistochemical results indicated that the expression level of CXCL14 in colorectal carcinoma tissue was lower than that in normal tissues (Fig. 1D, P<0.01). The mean optical densities of CXCL14 in tumor specimens and normal cells were 0.5411 and 0.1769 , respectively. 


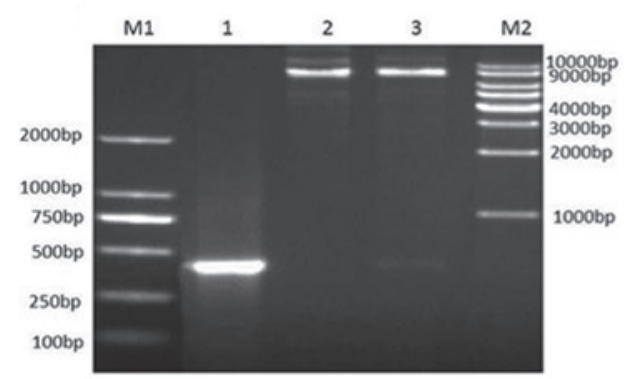

B

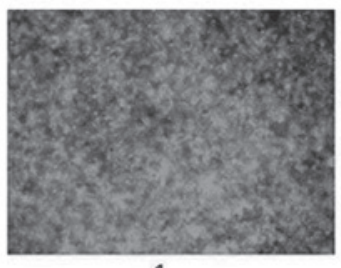

1

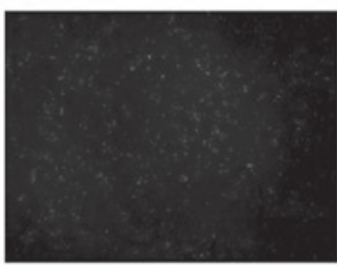

4

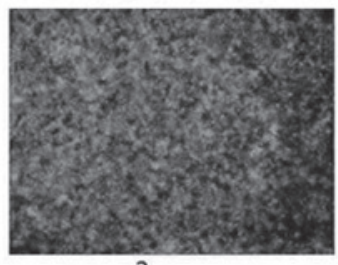

2

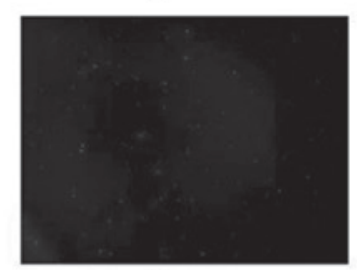

5

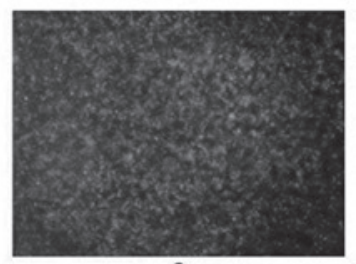

3

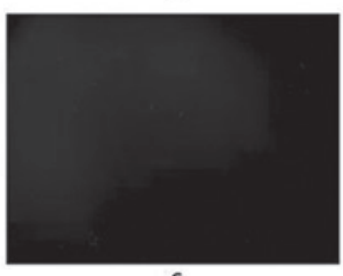

6

C

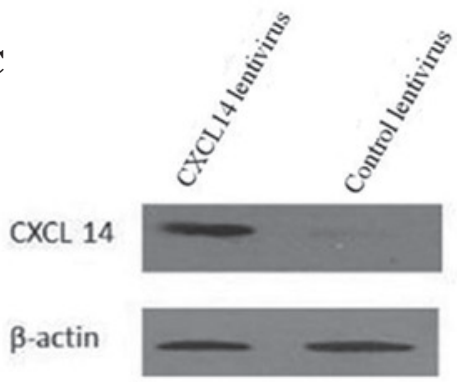

Figure 3.(A) Identification of PLenti6.3_CXCL14_IRES-EGFP recombinant plasmid.M1, 250 bp DNA ladder marker; lane 1,pLenti6.3_CXCL14_IRES-EGFP recombinant plasmid; lane 2, plasmid digested by NheI; lane 3, plasmid degested by NheI and AscI; M2, 1 kbp DNA ladder marker. (B) Titer of CXCL14-overexpressing lentivirus by GFP detection: $1,2 \times 10^{-3} \mathrm{ml}$ virus infection; $2,2 \times 10^{-4} \mathrm{ml}$ virus liquid; 3 , $2 \times 10^{-5} \mathrm{ml}$ virus infection; 4 , $2 \times 10^{-6} \mathrm{ml}$ virus

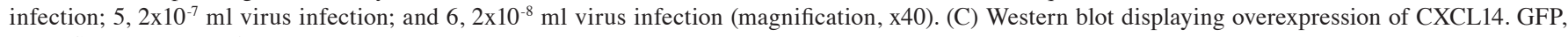
green fluorescent protein.

Correlation between CXCL14 expression and the clinicopathological features of colorectal carcinoma. Further analysis of the correlation between CXCL14 expression and the clinicopathological features of colorectal carcinoma indicated that the expression of CXCL14 protein is significantly correlated with tumor location, lymphatic metastasis and clinicopathological stages $(\mathrm{P}<0.05$; Table II). The relative expression level of CXCL14 in colorectal carcinoma tumor tissue with lymphatic metastasis was 0.146 (0.006 0.061), which is significantly lower than the level in tumor tissue without lymphatic metastasis $[0.215(0.004 \sim 0.120)](\mathrm{P}<0.05)$. The relative expression levels in colorectal carcinoma tissues at pathological stages III and IV were significantly lower than those of specimens at pathological stages I and II $(\mathrm{P}<0.05)$, whose relative expression levels were 0.146 (0.005 0.061) and 0.215(0.004 1.200), respectively. No significant correlation was identified between the expression levels of CXCL14 and age, gender, infiltration degree or tumor marker $(\mathrm{P}>0.05)$. According to the relative values of the mean optical density of CXCL14 proteins in paired tumor and normal tissues, specimens with a relative value $\geq 1 / 3$ were set as the high expression group and specimens with a relative value $<1 / 3$ were denoted as the low expression group. Kaplan-Meier survival analysis demonstrated that the five-year survival rate of the high expression group was $72.7 \%$, while in the low expression group it was $11.1 \%$ (Fig. 2). Therefore, CXCL14 may be an independent factor that positively affects prognosis.
CXCL14 overexpression influences proliferation and changes in cell cycle distributions of HT29 colorectal carcinoma cells. To analyze the effect of CXCL14 on colorectal carcinoma cells, a lentivirus that overexpressed CXCL14 was constructed. The PCR product ( $\sim 336 \mathrm{bp}$ ) was obtained from the constructed plasmid of recombinant pLenti6.3_CXCL14_IRES-EGFP. Nhel and Ascl double enzyme digestions also revealed that the CXCL14 gene had been successfully cloned into the vectors (Fig. 3A). DNA sequencing further verified the successful construction of a recombinant plasmid. The CXCL14-overexpressing lentivirus was further packaged by infecting 293T cells for $48 \mathrm{~h}$. The virus titer was detected through the enhanced green fluorescent protein (EGFP) carried by the virus. As demonstrated in Fig. 3B, the cells expressing EGFP were detected in cells infected with $2 \times 10^{-8} \mathrm{ml}$ virus and the titer of the virus was calculated as $1.2 \times 10^{9} \mathrm{TU} / \mathrm{ml}$. To confirm the expression of CXCL14, HT29 colorectal carcinoma cells were transfected with the CXCL14 lentivirus for $48 \mathrm{~h}$ followed by CXCL14 protein detection with western blotting. Compared with the lentivirus control, CXCL14 expression increased markedly in the cells transfected with the CXCL14 lentivirus (Fig. 3C).

Further investigation of the effect of CXCL14 overexpression in HT29 cells. Ectopic expression of CXCL14 led to a significant reduction in the viability of the HT29 cells, compared with the group transfected with the control lentivirus (Fig. 4A; $\mathrm{P}<0.05$ ). The cell viabilities in the CXCL14-overexpression and control 
A

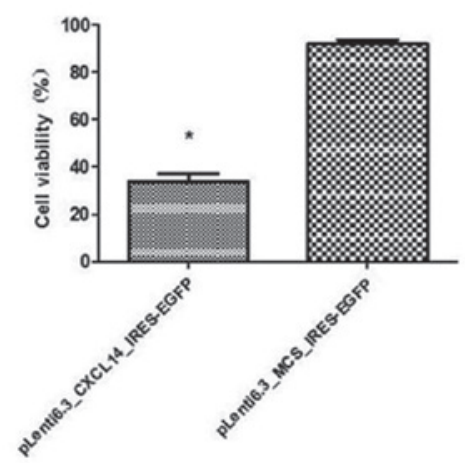

C

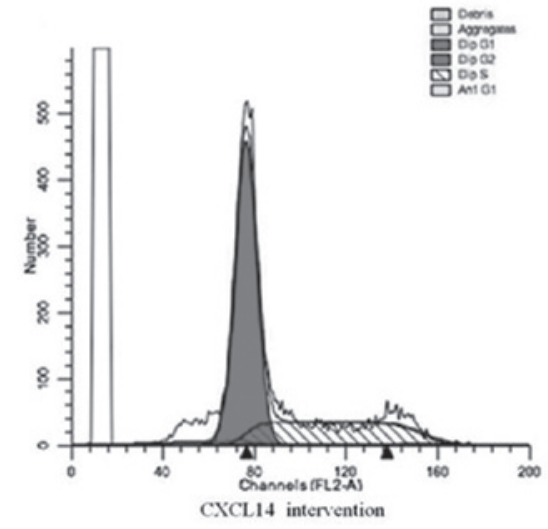

B
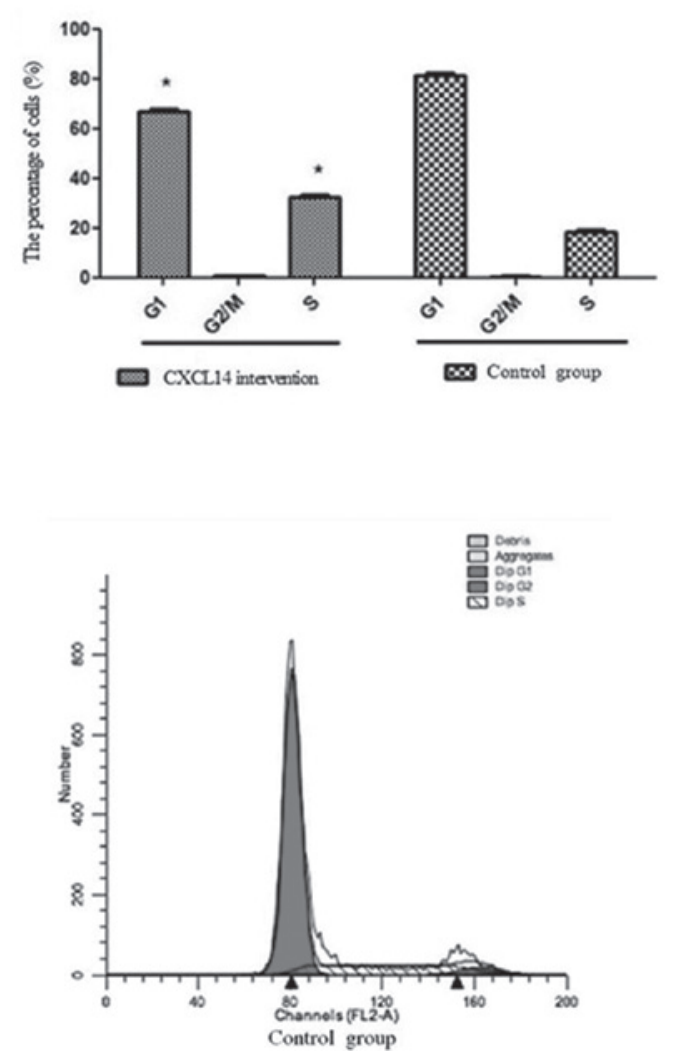

Figure 4. Overexpression of CXCL14 in HT29 colorectal carcinoma cells. (A) Cell viability assay of CXCL14-overexpressing cells. ${ }^{*} \mathrm{P}<0.05$ vs. control. (B) The percentage of cells in different cell cycle stages. $\mathrm{P}<0.05$ vs. control; (C) Cell cycle distributions were detected by flow cytometry at different stages.

groups were $96.47 \pm 2.53 \%$ and $36.56 \pm 5.47 \%$, respectively. FurtherFCManalysis indicated that the CXCL14-overexpression group presented a lower percentage of cells in the $\mathrm{G}_{1}$ stage $(67.46 \pm 0.92 \%)$ compared with the control group $(82.34 \pm 0.75 \%)$ $(\mathrm{P}=0.02)$; and a significantly higher percentage of cells in the $S$ stage $(36.47 \pm 0.59)$ compared with the control group $(21.97 \pm 0.64 \%)(\mathrm{P}=0.01)$ (Fig. 4B). No significant difference between the two groups was observed in the percentages of cells in the $\mathrm{G}_{2} / \mathrm{M}$ stage. These results suggest that the inhibition of HT29 cell proliferation by CXCL14 overexpression was mainly due to cell-cycle arrest at the $\mathrm{G}_{0} / \mathrm{G}_{1}$ stage (Fig. 4B and C).

\section{Discussion}

Chemokines can be sorted into inflammatory and self-stable sub-functional families (36). Chemokines are important in chemotaxis, i.e. the adhesion and migration of leukocytes, in addition to being influential in pro-inflammatory reactions $(37,38)$. Chemokines can also control the migration of immune cells from lymphoid to non-lymphoid tissues in a stable condition, and therefore function in immunological surveillance $(39,40)$. It has been reported that cells in tumor microenvironments are able to secrete several chemokines to regulate basic biological processes in tumor cells and normal cells, such as angiogenesis and specific immune activation of host and tumor cell proliferation (41). Therefore, chemokines are essential for the genesis, development and metastasis of tumors $(41,42)$.

CXCL14, consisting of 77 amino acids, is a novel member of the chemokine family and is crucial in maintaining a self-stable physiological function. When stimulated by lipopolysaccharide or Prostaglandin E2, peripheral monocytes have been indicated to be chemoattracted to sites of high CXCL14 expression $(12,39)$. Therefore, CXCL14 may be associated with the homeostasis of monocyte differentiation into macrophagocytes in tissues $(12,13,17)$.

To analyze the association between CXCL14 expression and colorectal carcinoma in the current study, the mRNA and protein expression levels of CXCL14 in colorectal carcinoma and adjacent normal tissues were detected using RT-qPCR and immunohistochemistry. Consistent with the results reported by a number of previous tumor-related studies (23-28), the present study detected that the expression levels of CXCL14 in colorectal carcinoma tissues were significantly lower than those in normal tissues. The current study did contradict the findings of Zeng et al (32), but was consistent with the results of Cao et al (33). In order to diminish the occurrence of experimental errors, a parallel immunohistochemical analysis was conducted using the method described by Zeng et al (32). The results from the parallel study were concurrent and indicated repeatedly that the expression levels of CXCL14 in colorectal carcinoma were reduced compared with levels in normal tissues. This further supports the hypothesis that the lack of CXCL14 expression in colorectal carcinoma may result in local immune deficiencies (including attenuated immune surveillance, immune evasion, weakened presentation of antigens and a disordered internal immune environment) caused by low permeability of immune cells in tissues (14). An analysis of the correlation of clinical features indicated that the expression level of CXCL14 in colorectal carcinoma 
tissue with lymphoid metastasis was significantly lower than that of tumor tissue without lymphoid metastasis; the relative expression levels of CXCL14 in colorectal carcinoma tissue at pathological stages III and IV were lower than those of specimens at stages I and II. Additionally, the expression levels of CXCL14 in tumor tissues were significantly correlated with the prognosis of colorectal carcinoma. These findings suggest that downregulation of CXCL14 expression may contribute to the more aggressive phenotype of colorectal carcinoma.

In addition to anticancer immune mechanisms, CXCL14 may suppress tumor vasculature by inhibiting the chemotaxis of vascular smooth muscle cells and the formation of microvascular systems $(16,19,21)$, and therefore suppress the metabolism and growth of a tumor. In addition, CXCL14 may also influence the proliferation, invasion and migration of tumor cells via auto/paracrine pathways $(24,43,44)$. It is controversial whether CXCL14 expression levels are elevated in prostate and pancreatic cancer (29-31). However, endogenously expressed CXCL14 has been demonstrated to promote the growth and invasiveness of breast and pancreatic cancer cells $(31,45)$.

In order to analyze the direct effect of CXCL14 on colorectal carcinoma cells in the present study, pLenti6.3_CXCL14_IRES-EGFP vectors containing an IRES sequence and enhanced green fluorescent protein (EGFP) were constructed to produce lentiviral overexpression of CXCL14. This method enabled rapid analysis of CXCL14 overexpression through the detection of EGFP. The successful construction of CXCL14-overexpressing lentivirus was confirmed by immunoblotting using CXCL14-specific monoclonal antibodies of cells transfected with the CXCL14 lentivirus. When HT29 cells were transfected with the CXCL14 lentivirus, the proliferation of HT29 cells was significantly inhibited. FCM analysis indicated that the overexpression of CXCL14 in HR29 cells promoted cell cycle arrest in the $\mathrm{G}_{1}$ stage. The results of the current study were consistent with the results reported by Wang et al (28) in hepatocellular carcinoma cells.

In conclusion, the present study further suggests that the downregulated expression levels of CXCL14 protein and mRNA in colorectal carcinoma tissues influence the local immune response of the tumor. In addition, the CXCL14 gene serves as a potential tumor-inhibiting gene in colorectal carcinoma. This characterization of the expression levels of CXCL14 in tumor tissues may provide a novel clinical auxiliary index for future treatment and prognosis evaluation of colorectal carcinoma.

\section{Acknowledgements}

The present study was supported by grants from the Department of Education, Zhejiang (grant no. Y201327980); the Taizhou Science and Technology Bureau (grant no. 1301ky40); and the Zhejiang Science and Technology Bureau (grant nos. 2012C33126 and 2012C37080). These sponsors provided the funding for the experiments and the collection of specimens.

\section{References}

1. Jemal A, Siegel R, Xu J and Ward E: Cancer statistics, 2010. CA Cancer J Clin 60: 277-300, 2010.

2. Devaud C, John LB, Westwood JA, Darcy PK and Kershaw MH: Immune modulation of the tumor microenvironment for enhancing cancer immunotherapy. Oncoimmunology 2: e25961, 2013.
3. Allen SJ, Crown SE and Handel TM: Chemokine: receptor structure, interactions, and antagonism. Annu Rev Immunol 25: 787-820, 2007.

4. Mellado M, Rodríguez-Frade JM, Mañes S and Martínez-AC: Chemokine signaling and functional responses: the role of receptor dimerization and TK pathway activation. Annu Rev Immunol 19: 397-421, 2001.

5. Sallusto F, Mackay CR and Lanzavecchia A: The role of chemokine receptors in primary, effector, and memory immune responses. Annu Rev Immunol 18: 593-620, 2000.

6. Ruffini PA, Morandi P, Cabioglu N, Altundag K and Cristofanilli M: Manipulating the chemokine-chemokine receptor network to treat cancer. Cancer 109: 2392-2404, 2007.

7. Mantovani A, Savino B, Locati M, Zammataro L, Allavena P and Bonecchi R: The chemokine system in cancer biology and therapy. Cytokine Growth Factor Rev 21: 27-39, 2010.

8. Uchida H, Iwashita Y, Sasaki A, Shibata K, Matsumoto T, Ohta $\mathrm{M}$ and Kitano S: Chemokine receptor CCR6 as a prognostic factor after hepatic resection for hepatocellular carcinoma. J Gastroenterol Hepatol 21: 161-168, 2006.

9. Ghadjar P, Coupland SE, Na IK, Noutsias M, Letsch A, Stroux A, Bauer S, Buhr HJ, Thiel E, Scheibenbogen C and Keilholz U: Chemokine receptor CCR6 expression level and liver metastases in colorectal cancer. J Clin Oncol 24: 1910-1916, 2006.

10. Hojo S, Koizumi K, Tsuneyama K, Arita Y, Cui Z, Shinohara K, Minami T, et al: High-level expression of chemokine CXCL16 by tumor cells correlates with a good prognosis and increased tumor-infiltrating lymphocytes in colorectal cancer. Cancer Res 67: 4725-4731, 2007.

11. Hromas R,BroxmeyerHE,KimC,NakshatriH,Christopherson KII, Azam $\mathrm{M}$ and Hou YH: Cloning of BRAK, a novel divergent CXC chemokine preferentially expressed in normal versus malignant cells. Biochem Biophys Res Commun 255: 703-706, 1999.

12. Frederick MJ, Henderson Y, Xu X, Deavers MT, Sahin AA, Wu H, Lewis DE, El-Naggar AK and Clayman GL: In vivo expression of the novel CXC chemokine BRAK in normal and cancerous human tissue. Am J Pathol 156: 1937-1950, 2000.

13. Meuter S and Moser B: Constitutive expression of CXCL14 in healthy human and murine epithelial tissues. Cytokine 44: 248-255, 2008.

14. Starnes T, Rasila KK, Robertson MJ, Brahmi Z, Dahl R, Christopherson K and Hromas R: The chemokine CXCL14 (BRAK) stimulates activated NK cell migration: implications for the downregulation of CXCL14 in malignancy. Exp Hematol 34: 1101-1105, 2006.

15. Juremalm M and Nilsson G: Chemokine receptor expression by mast cells. Chem Immunol Allergy 87: 130-144, 2005.

16. Shellenberger TD, Wang M, Gujrati M, Jayakumar A, Strieter RM, Burdick MD, Ioannides CG, Efferson CL, El-Naggar AK, Roberts D, et al: BRAK/CXCL14 is a potent inhibitor of angiogenesis and a chemotactic factor for immature dendritic cells. Cancer Res 64: 8262-8270, 2004.

17. Sleeman MA, Fraser JK, Murison JG, Kelly SL, Prestidge RL, Palmer DJ, Watson JD and Kumble KD: B cell- and monocyte-activating chemokine (BMAC), a novel non-ELR alpha-chemokine. Int Immunol 12: 677-689, 2000.

18. Kurth I, Willimann K, Schaerli P, Hunziker T, Clark-Lewis I and Moser B: Monocyte selectivity and tissue localization suggests a role for breast and kidney-expressed chemokine (BRAK) in macrophage development. J Exp Med 194: 855-861, 2001.

19. Hara T and Nakayama Y: CXCL14 and insulin action. Vitam Horm 80: 107-123, 2009.

20. Tanegashima K, Okamoto S, Nakayama Y, Taya C, Shitara H, Ishii R, Yonekawa H, Minokoshi Y and Hara T: CXCL14 deficiency in mice attenuates obesity and inhibits feeding behavior in a novel environment. PLoS One 5: e10321, 2010.

21. Maerki C, Meuter S, Liebi M, Muhlemann K, Frederick MJ, Yawalkar N, Moser B and Wolf M: Potent and broad-spectrum antimicrobial activity of CXCL14 suggests an immediate role in skin infections. J Immunol 182: 507-514, 2009.

22. Lindberg J, af Klint E, Catrina AI, Nilsson P, Klareskog L, Ulfgren AK and Lundeberg J: Effect of infliximab on mRNA expression profiles in synovial tissue of rheumatoid arthritis patients. Arthritis Res Ther 8: R179, 2006.

23. Hara $\mathrm{T}$ and Tanegashima $\mathrm{K}$ : Pleiotropic functions of the CXC-type chemokine CXCL14 in mammals. J Biochem 151: 469-476, 2012.

24. Tessema M, Klinge DM, Yingling CM, Do K, Van Neste L and Belinsky SA: Re-expression of CXCL14, a common target for epigenetic silencing in lung cancer, induces tumor necrosis. Oncogene 29: 5159-5170, 2010 
25. Gu XL, Ou ZL, Lin FJ, Yang XL, Luo JM, Shen ZZ and Shao ZM: Expression of CXCL14 and its anticancer role in breast cancer. Breast Cancer Res Treat 135: 725-735, 2012.

26. Ozawa S, Kato Y, Ito S, Komori R, Shiiki N, Tsukinoki K, Ozono S, Maehata Y, et al: Restoration of BRAK/ CXCL14 gene expression by gefitinib is associated with antitumor efficacy of the drug in head and neck squamous cell carcinoma. Cancer Sci 100: 2202-2209, 2009.

27. Hu C, Lin F, Zhu G, Xue X, Ding Y, Zhao Z, Zhang L and Shen X: Abnormal hypermethylation of promoter region downregulates chemokine CXC ligand 14 expression in gastric cancer. Int J Oncol 43: 1487-1494, 2013.

28. Wang W, Huang P, Zhang L, Wei J, Xie Q, Sun Q, Zhou X, Xie H, Zhou L and Zheng S: Antitumor efficacy of C-X-C motif chemokine ligand 14 in hepatocellular carcinoma in vitro and in vivo. Cancer Sci 104: 1523-1531, 2013.

29. Song EY, Shurin MR, Tourkova IL, Gutkin DW and Shurin GV: Epigenetic mechanisms of promigratory chemokine CXCL14 regulation in human prostate cancer cells. Cancer Res 70: 4394-4401, 2010.

30. Augsten M, Hagglof C, Olsson E, Stolz C, Tsagozis P, Levchenko T, Frederick MJ, Borg A, Micke P, Egevad L and Ostman A: CXCL14 is an autocrine growth factor for fibroblasts and acts as a multi-modal stimulator of prostate tumor growth Proc Natl Acad Sci USA 106: 3414-3419, 2009.

31. Wente MN, Mayer C, Gaida MM, Michalski CW, Giese T, Bergmann F, Giese NA, Büchler MW and Friess H: CXCL14 expression and potential function in pancreatic cancer. Cancer Lett 259: 209-217, 2008

32. Zeng J, Yang X, Cheng L, Liu R, Lei Y, Dong D, Li F, Lau QC, et al: Chemokine CXCL14 is associated with prognosis in patients with colorectal carcinoma after curative resection. J Transl Med 11: 6, 2013.

33. Cao B, Yang Y, Pan Y, Jia Y, Brock MV, Herman JG and Guo M: Epigenetic silencing of CXCL14 induced colorectal cancer migration and invasion. Discov Med 16: 137-147, 2013.

34. Winawer SJ, Krabshuis J, Lambert R, O'Brien M and Fried M; World Gastroenterology Organization Guidelines Committee: Cascade colorectal cancer screening guidelines: a global conceptual model. J Chin Gastroenterol 45: 297-300, 2011.
35. Benson AB 3rd, Bekaii-Saab T, Chan E, Chen YJ, Choti MA, Cooper HS, et al: Localized colon cancer, version 3.2013: featured updates to the NCCN Guidelines. J Natl Compr Canc Netw 11: 519-528, 2013

36. Zlotnik A and Yoshie O: Chemokines: a new classification system and their role in immunity. Immunity 12: 121-127, 2000.

37. Campanelli AP, Brodskyn CI, Boaventura V, Silva C, Roselino AM, Costa J, Saldanha AC, de Freitas LA, et al: Chemokines and chemokine receptors coordinate the inflammatory immune response in human cutaneous leishmaniasis. Hum Immunol 71: 1220-1227, 2010.

38. Wong MM and Fish EN: Chemokines: attractive mediators of the immune response. Semin Immunol 15: 5-14, 2003.

39. Moser B, Wolf M, Walz A and Loetscher P: Chemokines: multiple levels of leukocyte migration control. Trends Immunol 25: 75-84, 2004.

40. Krieg Cand Boyman O: The role of chemokines in cancer immune surveillance by the adaptive immune system. Semin Cancer Biol 19: 76-83, 2009.

41. Balkwill FR: The chemokine system and cancer. J Pathol 226: 148-157, 2012.

42. Zlotnik A, Burkhardt AM and Homey B: Homeostatic chemokine receptors and organ-specific metastasis. Nat Rev Immunol 11: 597-606, 2011

43. Shurin GV, Ferris RL, Tourkova IL, Perez L, Lokshin A, Balkir L, Collins B, Chatta GS and Shurin MR: Loss of new chemokine CXCL14 in tumor tissue is associated with low infiltration by dendritic cells (DC), while restoration of human CXCL14 expression in tumor cells causes attraction of DC both in vitro and in vivo. J Immunol 174: 5490-5498, 2005.

44. Izukuri K, Suzuki K, Yajima N, Ozawa S, Ito S, Kubota E and Hata R: Chemokine CXCL14/BRAK transgenic mice suppress growth of carcinoma cell transplants. [corrected]. Transgenic Res 19: 1109-1117, 2010.

45. Allinen M, Beroukhim R, Cai L, Brennan C, Lahti-Domenici J, Huang $\mathrm{H}$, et al: Molecular characterization of the tumor microenvironment in breast cancer. Cancer Cell 6: 17-32, 2004. 